\title{
Paramedics and Physician Assistants in Israel
}

\author{
Roderick S. Hooker(D)
}

\begin{abstract}
Israeli emergency medicine is undergoing change. The paramedic is experiencing high separation rates because the position is understaffed, overworked, and underpaid. Physician assistants (PAs) were introduced into the emergency department by training paramedics and to date they seem satisfied with this new role. Experience in other countries indicates that PAs can improve access to care, reduce errors, increase efficiency and have satisfying roles in health systems. The Israeli health system will need to determine if additional roles for PAs will be accepted by the public and physicians alike.
\end{abstract}

Keywords: Trauma, Burnout, Task transfer, Physician associates

\section{Introduction}

As of 2018, Israel had 3.1 clinically active physicians per capita, close to the median (3.2) of other countries highlighted in a report from the OECD [Organization for Economic Cooperation and Development] [1]. The availability of clinically active physicians in Israel is about $20 \%$ higher than in the U.S. (Fig. 1).

A number of attributes are notable about Israel: fiscal performance is rated good, strong macroeconomic growth is underway, unemployment is low, and its citizens enjoy universal healthcare [2]. Nonetheless, Israel is also struggling with some health professional issues and one, emergency medicine, is at the forefront. The challenge is the growing number of patients and an aging population without concurrent growth in staffing levels in emergency departments (EDs). Shortages in emergency medical staff have led to long waiting times, burnout, dissatisfied patients, and inefficient treatment [3].

In 2019 two papers were published in this journal about Israeli emergency medicine - with one focused on paramedics and the other focused on physician assistants (PAs) $[3,4]$. Dopelt et al. described Israeli paramedics as spread thinly, about 8 per 100,000, when compared to the US with approximately 25 per 100,000 (https://www.bls.gov/oes/ current/oes292041.htm). They report that 73\% depart after 5 years and $93 \%$ have left their paramedic role after 10 years

Correspondence: rodhooker@msn.com

Israel Journal of Health Policy Research, 115917 NE Union Rd, Unit 45, Ridgefield, WA 98642-8706, USA
- a high rate of turnover compared with most other health professions. Various reasons are offered for the Israeli paramedics' departure. "I felt that I had no career advancement opportunities" ranked high on the list $-83 \%$.

Maoz-Breuer and colleagues discuss the introduction of PAs into Israeli EDs. Two graduation cohorts of 30 each have been deployed in 17 of the 34 EDs around the country. All of the graduates were paramedics, and all were part of a pilot study undertaken by the Ministry of Health to see if an unsatisfactory phase in the career of a paramedic can serve as a springboard for a more sustaining one. In the Maoz-Breuer et al. paper, the survey of the 'former-paramedics-now-PAs' reported personal fulfillment, career prospects, and wage improvement as leading reasons for job or role satisfaction.

\section{Discussion}

Introducing PAs into a healthcare system is not new. As of this writing there are 19 countries with some form of PA and many others with comparable health professionals such as assistant medical officers, clinical officer, or feldshers $[5,6]$. How they are defined and the roles they provide are constantly changing as new technology alters the healthcare landscape, populations age and grow, and policy is adjusted to accommodate supply and demand.

PAs and their counterparts offer flexibility in adaptation and deployment in diverse settings. This is facilitated by the educational system, since adjusting a PA 


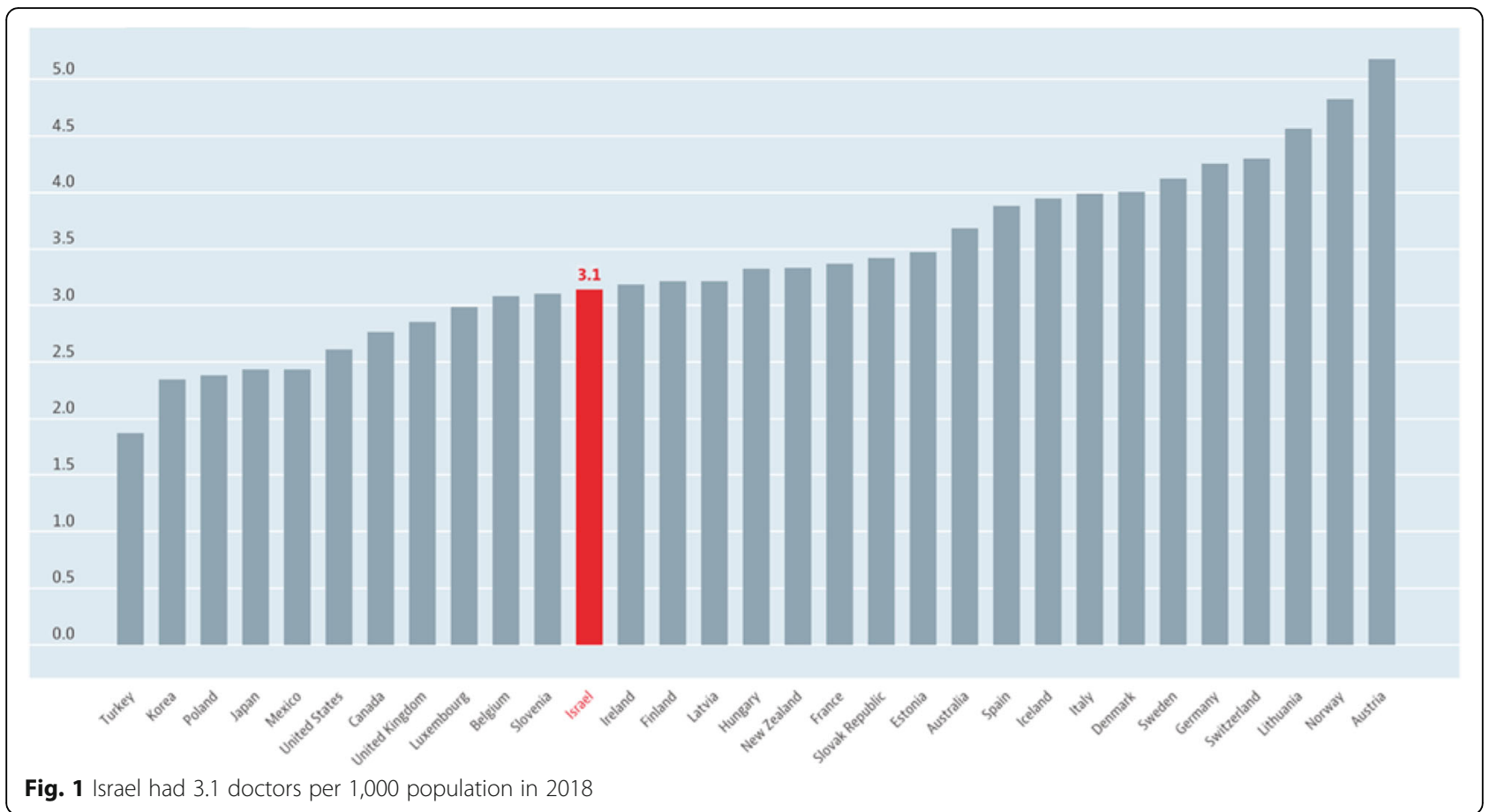

program's didactic and clinical syllabi is easier than changing the curriculum of a medical school. Attitudes also change. Early on in America, resistance to introducing PAs was felt in some sectors of society and a few medical specialties [7]. However, initial recruiting efforts relied on former corpsmen and medics, most having honed their skills during the Viet Nam war era, and that background seemed to resonate with citizens [8]. Patients' confidence grew and, after a few decades, the PAs became a recognized and respected group of health professionals [9]. Satisfaction came along quickly. Patients were willing to see any reliable health provider as long as their needs were met, and quality was not compromised [10].

One compelling reason to employ a worker who can be entrusted with a broad range of medical tasks, such as trauma care, is experience in the military where such care has been the realm of health professionals such as the surgeon, nurse, and medic working as a team. The Israeli Defense Forces Medical Corps is legendary not only for its training but for extending humanitarian aid where needed. The medic plays a particular role in this service [11]. The paramedic is the civilian counterpart, but, as the Dopelt group points out, the role is no longer satisfying over the long-term.

The PA in Israel is the newest member of a growing cadre of health professionals, and with it are opportunities to build upon the successes and failures of other nations [12]. Utilizing paramedics as PAs and employing them in EDs seems to make sense and seems to be working. The next step is to scale up the PA project to see if their adaptability can extend beyond the ED setting and into other medical venues. This will require examining the universal use of PAs, canvassing societal need, and modifying their roles to fit the needs of Israeli society.

PA roles across the globe vary widely and are expanding in ways unpredicted. One example includes facilitating joint replacement where the annual productivity of a Manitoba orthopaedic team increased by $42 \%$ just by adding a PA for pre- and post-operative patient assessment [13]. Management of complex diseases in US veterans by PAs produces outcomes indistinguishable from physicians but at a lower labor cost [14]. In the Netherlands, the hospital-based PA is taking on procedures normally reserved for medical and surgical specialized doctors, freeing them up for more complex tasks [15]. The New Zealand ED PAs were not only able to integrate smoothly with the existing team, but supervising physicians reported they added value by "the quality and safety of the work performed" [16]. In the UK the issues facing the British in accessing adequate healthcare led to the decision that they needed a large cadre of PAs. In the UK, PAs are called Physician Associates. Not only did the NHS fund 25 additional PA programs in the second decade but it incorporated them in The Royal College of Physicians [17].

One of the characteristics of the PA concept is the relationship between the PAs and physicians. In Ireland the definition of a PA is: "a healthcare professional trained in medicine who works as part of a medical team in partnership with doctors to provide medical care to patients" [18]. Outside of the military, the PA is generally not autonomous and instead defines him or herself as a team member - with the physician central to the 
group. This collaborative relationship seems to not only delineate their nature and role but appears to be the adaptation needed to the ever-changing dynamics of contemporary medicine. This physician-PA relationship is true for the Israeli PA in the same way it is for the PA in Australia, Germany, or any other location.

If Israel is to welcome PAs, the health organization pragmatist will want to know the evidence pertinent to their inclusion. For example, the willingness of patients to be seen by a PA needs to be assessed along with patients' satisfaction at having had their needs met. Other questions are a bit more challenging; for example, can a country's physician corps embrace the collaborative type of practice that PAs bring? Is a hierarchical system of medical authority open to the growing trend in teambased care when that team member is a PA? Will the phenomenon of growing physician burnout, which is emerging in a number of countries, be ameliorated as it has in sectors where PAs work in partnership with physicians [19]? If being a PA is career satisfying, will that have a carryover effect on their supervising physician [20]?

\section{Conclusion}

Israel is at the forefront of many medical and technological advances; and introducing PAs into a mature healthcare system, should be a very good addition to Israel's medical workforce. The early results in emergency medicine seem promising. The challenge will be extending this success, seeing if more paramedics can be attracted to becoming PAs rather than leaving healthcare entirely, and determining if the medical system and general public will embrace PA roles not only in the ED but in other fields as well.

\section{Abbreviations}

EDs: Emergency departments; OECD: Organization for economic cooperation and development; PA: Physician assistant or physician associate; U.S.: United States; UK: United Kingdom

\section{Acknowledgements}

None.

Availability of data

Not applicable, none used.

\section{Authors' contributions}

$100 \%$ by Roderick S. Hooker.

\section{Funding}

None.

\section{Ethics approval}

No ethics approval was sought, none was required. Waived.
Received: 15 December 2019 Accepted: 20 December 2019

Published online: 06 January 2020

\section{References}

1. OECD (2019), Doctors per 1,000 inhabitants, 2018 or latest available. doi: https://doi.org/10.1787/4355e1ec-en (Accessed November 2019).

2. OECD (2018), OECD economic surveys: Israel 2018, OECD Publishing, Paris, https://doi.org/https://doi.org/10.1787/eco_surveys-isr-2018-en. (Accessed November 2019).

3. Maoz-Breuer R, Berkowitz O, Nissanholtz-Gannot R. Integration of the first physician assistants into Israeli emergency departments-the physician assistants' perspective. Isr J Health Policy Res. 2019;8(1):4.

4. Dopelt K, Wacht O, Strugo R, Miller R, Kushnir T. Factors that affect Israeli paramedics' decision to quit the profession: a mixed methods study. Isr J Health Policy Res. 2019;8(1):78.

5. Rick TJ, Moshi DD. The Tanzanian assistant medical officer. J Am Acad PAs. 2018:31(4):43-7.

6. Ramer SC. The Russian feldsher: a PA prototype in transition. J Am Acad PAs. 2018;31(11):1-6.

7. Carlson $\mathrm{CL}$, Athelstan $\mathrm{GT}$. The physician's assistant: versions and diversions of a promising concept. JAMA. 1970;214(10):1855-61.

8. Cawley JF, Cawthon E, Hooker RS. Origins of the physician assistant movement in the United States. J Am Acad Physician Assist. 2012; 25(12):36-42.

9. Dill MJ, Pankow S, Erikson C, Shipman S. Survey shows consumers open to a greater role for physician assistants and nurse practitioners. Health Aff. 2013;32(6):1135-42.

10. Hooker RS, Moloney-Johns A, MacFarland M. Patient satisfaction with physician assistant/associate care: an international scoping review. Hum Resour Health. 2019;17(104):1-11.

11. Glick Y, Baruch EN, Tsur AM, Berg AL, Yifrah D, Yitzhak A, et al. Extending a helping hand: a comparison of Israel defense forces medical corps humanitarian aid field hospitals. Isr Med Assoc J: IMAJ. 2016;18(10):581-5.

12. Berkowitz O, Gelbshtein U, Segal I, Jacobson E. The new Israeli PA. J Am Acad PAs. 2018:31(7):46-8.

13. Bohm ER, Dunbar M, Pitman D, Rhule C, Araneta J. Experience with physician assistants in a Canadian arthroplasty program. Can J Surg. 2010; 53(2):103.

14. Morgan PA, Smith VA, Berkowitz TS, Edelman D, Van Houtven $\mathrm{CH}$, Woolson $\mathrm{SL}$, et al. Impact of physicians, nurse practitioners, and physician assistants on utilization and costs for complex patients. Health Aff. 2019;38(6):1028-36.

15. Brink VD GTWJ, Kouwen AJ, Hooker RS, Vermeulen H, Laurant MGH. An activity analysis of Dutch hospital-based physician assistants and nurse practitioners. Hum Res Health. 2019; 17: 78, 1-8.

16. Limited S. Phase II of the physician assistant demonstrations evaluation report: report for health workforce New Zealand. Wellington: Ministry of Health; 2015.

17. Ritsema TS, Roberts KA, Watkins JS. Explosive growth in British physician associate education since 2008. J Phys Assist Educ. 2019;30(1):57-60.

18. Joyce P, Arnett R, Hill A, Hooker RS. Patient willingness to be seen by a physician associate in Ireland. Int J Healthcare. 2018; 4(2): 1-9.

19. Helfrich CD, Dolan ED, Simonetti J, Reid RJ, Joos S, Wakefield BJ, et al. Elements of team-based care in a patient-centered medical home are associated with lower burnout among VA primary care employees. J Gen Intern Med. 2014:29(2):659-66.

20. Hooker RS, Kuilman L, Everett CM. Physician assistant job satisfaction: a narrative review of the empirical research. J Phys Assist Educ. 2015;26(4): $176-86$.

\section{Publisher's Note}

Springer Nature remains neutral with regard to jurisdictional claims in published maps and institutional affiliations.

Consent for publication

Is agreed. 